\title{
Correction to: Questions as information types
}

\section{Ivano Ciardelli ${ }^{1}$}

Published online: 11 July 2019

(c) The Author(s) 2019

\section{Correction to: Synthese (2018) 195:321-365 \\ https://doi.org/10.1007/s11229-016-1221-y}

Unfortunately, the Acknowledgements section is missing from the original publication.

Acknowledgements This project has received funding from the European Research Council (ERC) under the European Union's Horizon 2020 research and innovation programme (Grant Agreement No. 680220).

Publisher's Note Springer Nature remains neutral with regard to jurisdictional claims in published maps and institutional affiliations.

The original article can be found online at https://doi.org/10.1007/s11229-016-1221-y.

$凶 \quad$ Ivano Ciardelli

i.a.ciardelli@uva.nl

1 Institute for Logic, Language, and Computation, University of Amsterdam, Amsterdam, The Netherlands 